\title{
The Assesses Impact Of Motherly Awareness On Pediatric Vaccine Uptake
}

\author{
Sadaf Abid Ali \\ \& \\ Sumera Ishrat \\ Department of Social Work \\ University of Karachi
}

\begin{abstract}
Pediatric vaccination is the greatest instrument for children' health. It avoids infection and viruses of under 2 years of children. Numerous nations are appearing unwilling for pediatric immunization. There is a vital barrier to pediatric vaccination, which is associated with the lack of maternal awareness (line remove)The current study is designed to evaluate the childhood vaccination-related diseases, mother's awareness, practice, perception and these impact on the pediatric vaccination status, additionally, to know the children's health conditions level in Gadap town, Karachi Pakistan. This study assesses the impact of childhood vaccination as protecting shield which associated with the mother's awareness, practices as well as the mothers' perception. Evaluate the childhood immunization's benefits and health risk for not choosing vaccination of their children and its effect on childhood vaccination status. In this study purposive technique of non-probability sampling is used to select sample of mothers whose children age up to 2 years. This selection is done by keeping in mind the objective of the research. The total sample was 280 who were under two years of children's mothers. The research design was qualitative and quantitative, furthermore, the exploratory design was used, and the in-depth interviews have been conducted from each mother. The research instrument has personal information, pediatric vaccination status, pediatric vaccine practice, mothers awareness about benefits, health risk, vaccine-preventable diseases related information, additionally, know the mother's Perception regarding the pediatric mortality and morbidity ,furthermore, the level of motherly awareness and pediatric vaccination practice which were scored according to mother's answers.
\end{abstract}

Keywords: Assesses, Motherly, Awareness, Pediatric, Vaccine.

$$
\begin{aligned}
& \text { تلخيص }
\end{aligned}
$$

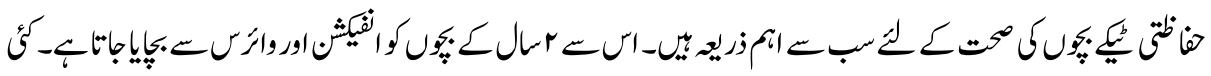

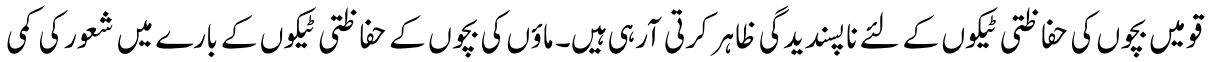

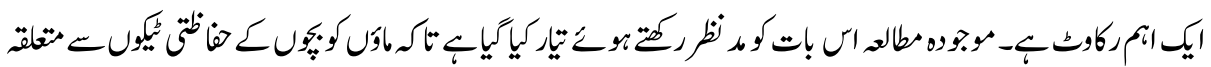

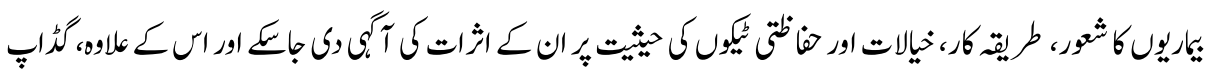




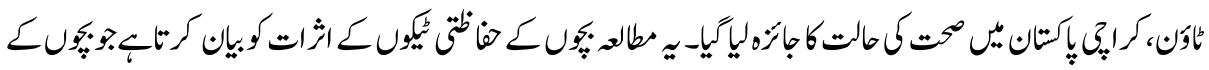

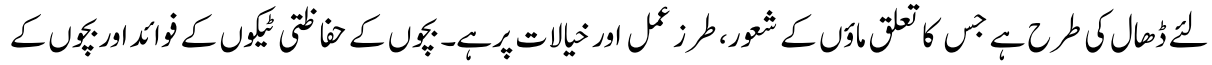

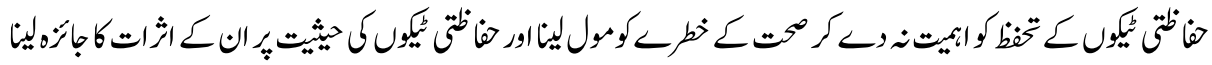

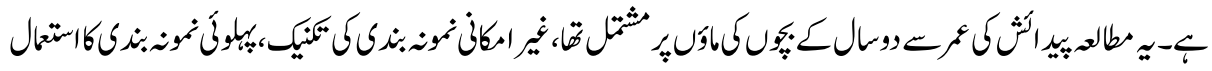

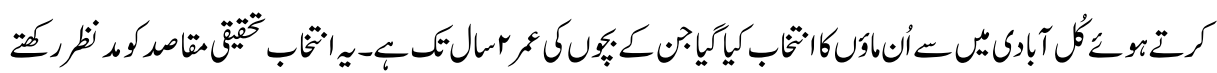

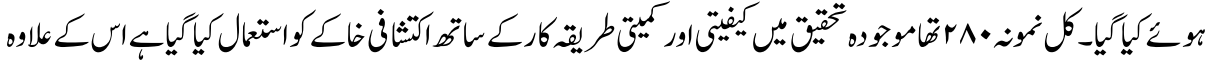

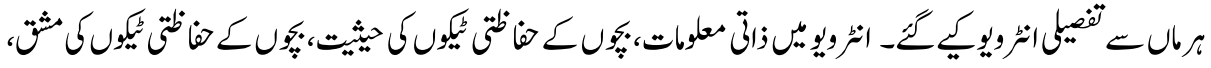

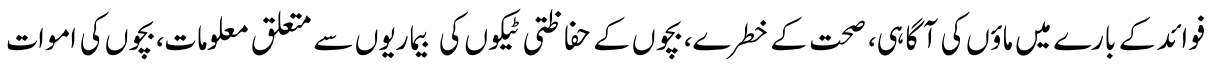

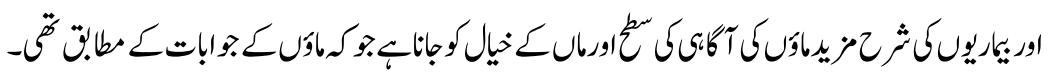

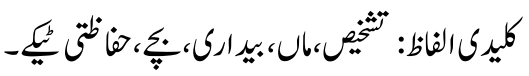

\section{Introduction}

According to the World Health Organization (1947) Pediatric health means that the children ought to be well physically, psychologically and particularly in the absence of wellness (WHO, 1979). Children are the upcoming part of each state and therefore, the main concern of all the countries, communities and humanities ought to be safeguarded for his or her healthy progress and physical development (Tomes \& Rickel, 1996). Children infections bring diseases and germs and viruses instigated from the infection (Holdsworth \& Robinson, 2008). It is observed that zero to 2 years of children get affected earlier as well as the deaths in the newborn period are frequently caused by diseases, mother's malnutrition, absence of mother's awareness, Mother's wrong perception, difficulties in children's delivery plus tetanus, pediatric low immune and illnesses are also influencing factors of children morbidity and mortality. Mention in the "The Convention on the Rights of the Child" the articles relevant to the right of the family life tells the convention validates the association between the right to family life and all other fundamental principles about child rights. According to (CRC, Art. 27) "Parties have positive duties to take appropriate measures to assist parents (and others responsible for the child) in providing an adequate standard of living for their children (Chernyshov, 2012). Every year, nearly 10 million zero to 2 years of children's are dying globally, moreover, in the world 42 republics are dealing with zero to 2 years of the child's death. Unambiguously South Asia and Sub-Saharan Africa encountered inconsistency in the death of under 2 years of children and these rates are growing every year (Rudan1, 2013). Globally, the zero to 2 years of children's death occurrence is 41 deaths per 1,000 live births in the years of 2016 (UNICEF, March 2018). According to WHO (2019) Pakistan comes in low-income regions, it is going through the poverty and illiteracy (WHO, 2019). However, healthiness system has been failed, especially, among the 2 years of children 
(Afzal, Yusuf. 2013). Furthermore, according to the UN it has unsuccessful to attain two key target sets in all South Asian countries, one is "Health for all" in 2000, $2^{\text {nd }}$ "Millennium Development Goals" in 2015 (United nation, 2015 \& WHO, 2013).

These mortality rates were because of pediatric vaccine-preventable diseases. The child mortality rates were EURO (European region) was 33\%. WPRO (Western Pacific) was $34 \%$. Additionally AMRO (American region) was 38\%, moreover, EMRO (Eastern Mediterranean region) was $62 \%$, and SEARO (South East Asia region) was $56 \%$, AFRO (African region) was 73\%, The, AFRO SEARO, and EMRO were the three regionsin the world which highly contributed the highest rates of child mortality (Nizar, Chagani, 2016). Pakistan is one of those counties, who has the 2 years of pediatric mortality higher than others country (UNICEF, 2018). Pediatric under 2 years of deaths because of measles disease is the main children's enemy as well as the killer, but degenerated almost $85 \%$ internationally, additionally nearly $89 \%$ in the important region, sub-Saharan Africa in the years of 2000(World Health Organization. 2010). Then nearly 14 main countries removed maternal as well as neonatal tetanus disease and tetanus casualty rate was $70 \%$ in newborns. Receiving percentage of pediatric pertussis, diphtheria, and tetanus vaccine (DTP) usually is the pointer of countries who are giving pediatric vaccines. In the year of 2017, the total global pediatric vaccine coverage rates of the $3^{\text {rd }}$ dose of the pediatric (DTP3) got $85 \%$ and got upgraded by $72 \%$ the years of 2000 , additionally $21 \%$ in the year of 1980 . But, progress needs to improve, almost 71 countries have not achieved the Global Vaccine Action Plan (GVAP). Internationally 19.9 million Pediatric of 1 year haven't received the all 3 doses of the DTP in the year of 2017, furthermore, 20.8 million children of 1 year have unsuccessful to take a single dose of the pediatric vaccine measles. Almost 123 million world's children were vaccinated in the year of 2017, however, many millions of children are still unvaccinated and suffering from mortality and morbidity. Around $40 \%$ which were nearly 8 million of the unvaccinated 1 year of children are living in low income setting, 10 countries have only $50 \%$ pediatric vaccine rate of DTP3 vaccine and similar measles vaccine, which are from, Central African Republic, Angola, Equatorial Guinea, Chad, Guinea, Ukraine, South Sudan, Nigeria, Syrian Arab Republic and Somalia. As well as a half $\%$ of children unvaccinated for DTP3 were living in these five nations which were: Pakistan, India, Indonesia, Nigeria and Ethiopia (Jennifer, Liang, 2018).

\section{Literature Review}

A study finding showed that there were great differences in mother awareness and the practice of Pediatric routine vaccination (UNICEF 2017). The Centers for Disease Control and Prevention (CDC) showed the study results on the National Immunization Safety which exposed that award mothers who supposed children vaccines were harmless more possible to get their children inoculated as related to mothers who were supposed that vaccines were unsafe (CDC, 2000). The research results explored in 2 countries, Pakistan and India there were the big misunderstanding and mothers were frightened vaccinations and doubtful regarding the ingredients (Benin, Wisler-Scher, Colson \& Shapiro, 2006). 
Children health Influences to increase acceptance of Pediatric vaccination against diseases (Payne, Townend, Jasseh, Lowe Jallow \& Kampmann, 2014). Mothers should be assured that children are not in danger and other children were securely immunized, outcomes of the awareness regarding the vaccination give the children faintness and the consequence get diseases, in many countries usually in mother's belief the natural immunity and retrieval after infections are healthier than the vaccination. Additionally, Worries about the vaccination reliability of source information about immunization and mothers don't believe in vaccine safety and afraid of life risks like death and disability (Wiysonge, Uthman, Ndumbe, \& Hussey, 2012).

Children's fully vaccination status in low-income countries are actually low (Rutherford, Dockerty, Jasseh, et al, 2009). It is esteemed 54.5 million children expire every year and 1 among eight of those dies following within the age of 02 (WHO, 2010). UN agency admissions up to a pair of 2.5 million expiries of under two years of children globally, whereas the vaccination rate obtaining the higher against infectious diseases (WHO, 2016) it confirmed that the children get appropriately immunized in early ninth months, they are safer than those children who don't vaccinate in that period. Creation's $1 / 5^{\text {th }}$ of neonatal which an estimated 19.5 million doesn't seem to be immunized. Yearly about 1.5 million died against the vaccine-preventable diseases. (WHO. 2018). In the year of 2016,nearly 4.2 million children have expired in one year of a child's life (UNICEF, 2017). Furthermore, Pediatric vaccination standing is rising day by day. Globally consistently the blow 2 years of child death rates have gotten a decrease. 1990 the infant death rate was the 37 within the 1,000 live childbirths, in the year of 2016 this rate was down 19 within the1, 000 live childbirths globally'(End Polio Pakistan, 2019)in the year of 1990, the neonatal mortality rate was 64.8 , within the 1,000 live childbirths, as well as getting down from 30.5 within the1, 000 live childbirths in the year of 2016 globally (The World Bank, 2017). Equally, globally throughout the year of 1990, five years of children's expiry rates were93\%within the1, 000 live births which got down to 2016, 41 within the 1,000 live childbirths. However, in 1990 under 1 year of children' death rate was as high as 8.8 million, then globally reduced as low as 4.2 million in the year of 2016 (The World Bank, 2017).

The population, urban center, Karachi city is 14,910,352 in line with 2017 Asian country Pakistan census (Revolvy, L. (2018). About half the population of the Karachi survives in rural areas (Revolvy, L. (2018). The blow five years of children's expiry rates in the rural areas is 2.5 quite alternative cities rates (WHO, 2017). Individuals living in rural generally live missing with basic necessities and community facilities, lack of maternal healthcare practice, an absence of maternal awareness low level of awareness. Typically, mother's wrong perceptions about regular vaccine information are incorrect, lack of Expended Program of Immunization distribution facilities, poverty, illiteracy and robust ethical beliefs. All of those influences boost high Pediatric diseases and mortality rate (Nizar, Chagani, 2016, Ansari, 2015, Mathers, Lopez, \& Murray, 2006). 
Globally, these low rates reporting the childhood vaccination decreased status, on the other hand, it has continually kept on high in Pakistan (Lorenz, Khalid 2012 \& Encyclopedia, 2007). It means the healthcare situation of children, morbidity and death rate got higher in the rural areas of Karachi, Pakistan (Nizar Chagani, 2016).

In Pakistan, the Expanded Program on Immunizations was started in the year of 1978. The Pakistan federal Government is answerable of the vaccine in provision level, needles, cool chain tools, transportation, and health awareness material and vaccine awareness campaigns. ${ }^{38}$ Expanded Program on Immunization vaccines preventable diseases are one of the key purposes of high Pediatric diseases and death rates. Evidence proved that great Infant death rates found in low-income states. In Pakistan, the Expanded Program on Immunizations Pediatric vaccine coverage is still under below in contradiction of a child's immunity. According to the WHO procedures, the Pakistan health department makes available the vaccination schedule. The Expanded Program on Immunizations is sponsored by via the United Nations International Children's Fund. All health Services and Vaccines provide free in every district across Pakistan (Daily mail TV programe, 2018).

\section{Hurdles in Pediatric Vaccination}

This research study recognized the hurdles of Pediatric vaccination, access the mother's wrong perception, awareness, knowledge level of Pakistan vaccine-preventable diseases and mothers vaccination practices associated with the absence of Pediatric vaccination activities contribution of Gadap town.

This research study was to assess the mother's awareness about childhood vaccinations, access the mother's wrong perception, vaccines preventable diseases, vaccines benefits, leading cause of infant morbidity, knowledge of most common reasons for infant health risk, Pakistan childhood vaccination knowledge related disease, Consequences for not choosing childhood vaccination as health care, disease is the leading cause of infant morbidity in the area, knowledge of the Pakistan Expanded Program on Immunization, results of the vaccination status in the Gadap town. The research was conducted Age 0 to 02 children's mothers, this study was comprised the childhood routine vaccination schedule which suggested from the Pakistan EPI against vaccines preventable diseases such as tetanus, diphtheria, pertussis DTP, Haemophilus influenza type b (Hib), polio (OPV) IPV, hepatitis $b$, meningitis, measles, TB. The Pakistan vaccination schedulehas 3 doses of DTP, 3 doses Hib, 3 doses OPV doses, 3 doses pants, and 3 doses PCV doses. 2 doses measles (Vander Stoep \& Johnston, 2009).

\section{Study Area}

This study's research area is Gadap town. It is the main town of Karachi and its population is about 289,564 with the 8 union councils conferring from the census of Pakistan 1998. 
${ }^{41}$ additionally, UC 1 with the name of Murad Mammon Goth and its population is approximately 37, 888, UC 2 Darsana Chana its population is exactly 30, 470, UC 2 Gadap UC 3 with the population of 30,294 , Gujro UC4 its population is 49, 161 then UC 5 Songal with the population of 29, 540, then UC 6 Maymarabad and its population is 33, 739, UC7 Yousuf Goth population is 42, 387 and then UC 8 Manghopir with a population of 36, 253, The Gadap town is least developed town of Karachi and its poverty and illiterateness both are the fecund and health facilities are absent (PBS, 2017 \& PBS, 2018).

\section{Objectives}

- To assess the mother's practices of 0-2 years of Pediatric vaccination.

- To know the mother's awareness about Pediatric vaccination.

- To analysis the mother's perception regarding Pediatric mortality and morbidity.

\section{Research Methodology Research Design}

In order to assesses impact of motherly awareness on pediatric vaccine uptake the qualitative and qantitative research design have taken, the exploratory research helped to have the better understanding of the current research problem and explore the research topic with varying levels of indepth, moreover, this study adopted the primary data collection to gather information about the pediatric vaccination and mother awareness and associated factors affecting the pediatric vaccination status. The universe is Gadap town 8 union councils, 0 to 2 years of mothers were the population. Which nominated from the purposive sampling. The sample size was 280.Interviews have been taken with the open and closed-ended taller made questionnaire which included mothers' awareness about childhood vaccinations, access the mother's wrong perception, vaccines preventable diseases, vaccines benefits, leading cause of childhood morbidity, knowledge of most common reasons for children health risk, Pakistan childhood vaccination knowledge related disease, Consequences for not choosing pediatric vaccination as health care, disease is the leading cause of childhood morbidity in the area, knowledge of Pakistan. This study used statistical package for Social Sciences (SPSS) for data analysis and get considerable results.

\section{Results and Findings}

The results and research findings contributed chiefly understand the pediatric vaccination status and related factors like mothers' awareness about childhood vaccinations, vaccines preventable diseases, vaccine's benefits, a leading cause of childhood morbidity, knowledge of the most common reasons for children health risk, Pakistan childhood vaccination knowledge related disease. The study has used the descriptive statistics of understanding the level of pediatric vaccination status and related factors. 
Table: 1

Pediatric vaccination status

\begin{tabular}{|l|c|c|c|c|c|c|}
\hline \multirow{2}{*}{} & \multicolumn{2}{|c|}{ Vaccinated } & \multicolumn{2}{c|}{ Unvaccinated } & \multicolumn{2}{c|}{$\begin{array}{c}\text { Partially } \\
\text { Vaccinated }\end{array}$} \\
\cline { 2 - 7 } & $\mathbf{F}$ & $\mathbf{\%}$ & $\mathbf{F}$ & $\mathbf{\%}$ & $\mathbf{F}$ & $\%$ \\
\hline $\begin{array}{l}\text { Have your zero to two years } \\
\text { of children been vaccinated? }\end{array}$ & 90 & $32.14 \%$ & 120 & $42.85 \%$ & 70 & $25 \%$ \\
\hline Total & \multicolumn{3}{|c|}{$\mathbf{2 8 0}$} & \multicolumn{3}{|c|}{$\mathbf{1 0 0 \%}$} \\
\hline
\end{tabular}

Above table 01 maximum children 120 (42.85\%) were unvaccinated. While 90 (32.14\%) of the children were vaccinated. Though, 70 (25\%) of the children were partially vaccinated.

Table: 2

Pediatric vaccination awareness

\begin{tabular}{|c|c|c|c|c|c|c|}
\hline & \multicolumn{2}{|l|}{ Yes } & \multicolumn{2}{|l|}{ No } & \multicolumn{2}{|c|}{ Don't know } \\
\hline $\begin{array}{l}\text { Do you know about pediatric } \\
\text { vaccination? }\end{array}$ & 130 & $46.42 \%$ & 67 & $23.92 \%$ & 83 & $29.64 \%$ \\
\hline $\begin{array}{l}\text { Do you practice pediatric } \\
\text { vaccination? }\end{array}$ & 86 & $30.71 \%$ & 194 & $69.28 \%$ & 280 & $100 \%$ \\
\hline \multirow[t]{3}{*}{ Total } & \multicolumn{2}{|l|}{280} & \multicolumn{4}{|c|}{$100 \%$} \\
\hline & \multicolumn{3}{|l|}{ Yes } & \multicolumn{3}{|l|}{ No } \\
\hline & \multicolumn{2}{|l|}{$\mathrm{F}$} & $\%$ & $\mathrm{~F}$ & $\%$ & Total \\
\hline $\begin{array}{l}\text { Do you know the benefits of } \\
\text { immunization? }\end{array}$ & \multicolumn{2}{|l|}{91} & 32.5 & 122 & 43.57 & 280 \\
\hline \multicolumn{7}{|c|}{ Do you know about the Pakistan Expanded Program on Immunization (EPI)? } \\
\hline Understanding about the EPI & \multicolumn{3}{|c|}{$\mathrm{F}$} & \multicolumn{3}{|c|}{$\%$} \\
\hline Yes & \multicolumn{3}{|l|}{31} & \multicolumn{3}{|l|}{11.07} \\
\hline No & \multicolumn{3}{|l|}{63} & \multicolumn{3}{|l|}{22.5} \\
\hline Don't know & \multicolumn{3}{|l|}{186} & \multicolumn{3}{|c|}{66.42} \\
\hline Total & \multicolumn{3}{|l|}{280} & \multicolumn{3}{|c|}{$100 \%$} \\
\hline & \multicolumn{3}{|l|}{ Yes } & \multicolumn{2}{|c|}{ No } & \\
\hline $\begin{array}{l}\text { Do you know about the zero to } 2 \\
\text { years of pediatric-related diseases? }\end{array}$ & \multicolumn{2}{|l|}{29} & $10.35 \%$ & 251 & $89.64 \%$ & $\begin{array}{l}280 \\
100 \%\end{array}$ \\
\hline \multicolumn{7}{|c|}{ If yes, then what disease is the leading cause of childhood morbidity? } \\
\hline Leading Cause of pediatric morbidi & & & & & & $\%$ \\
\hline
\end{tabular}




\begin{tabular}{|c|c|c|c|c|}
\hline Poliomvelitis & \multicolumn{3}{|l|}{29} & 1367 \\
\hline Neonatal Tetanus & \multicolumn{3}{|l|}{16} & 7.54 \\
\hline Measles & \multicolumn{3}{|l|}{19} & 8.96 \\
\hline Diphtheria & \multicolumn{3}{|l|}{03} & 1.41 \\
\hline Pertussis & \multicolumn{3}{|l|}{04} & 1.88 \\
\hline Hepatitis B & \multicolumn{3}{|l|}{25} & 11.79 \\
\hline Hib Phenomena & \multicolumn{3}{|l|}{23} & 10.84 \\
\hline Meningitis & \multicolumn{3}{|l|}{00} & 0.00 \\
\hline Childhood Tuberculosis & \multicolumn{3}{|l|}{12} & 5.66 \\
\hline Jaundice & \multicolumn{3}{|l|}{09} & 4.24 \\
\hline Diarrhea & \multicolumn{3}{|l|}{29} & 13.67 \\
\hline Malaria & \multicolumn{3}{|l|}{14} & 6.60 \\
\hline Others (Specify) & \multicolumn{3}{|l|}{29} & 13.67 \\
\hline $\begin{array}{l}\text { Total (There is a possibility of } \\
\text { multiple) }\end{array}$ & \multicolumn{3}{|c|}{212} & $100 \%$ \\
\hline & \multicolumn{2}{|l|}{ Yes } & No & \\
\hline $\begin{array}{l}\text { Do you know in Pakistan Pediatric } \\
\text { vaccination been carried out for which } \\
\text { disease? }\end{array}$ & 63 & $22.5 \%$ & 217 & $77.5 \%$ \\
\hline
\end{tabular}

Table.02 confirm that mother had the Pediatric Vaccination awareness asked to indicate the awareness of the benefits of pediatric vaccination.

Mothers have awareness about Pediatric vaccination. Mothers 130 which was (46.42\%) had awareness about vaccination, followed by $83(29.64 \%)$ said they don't want to tell whether they have the awareness or not. Though, 67 (23.92\%) mothers said they didn't have awareness of pediatric vaccination. Though those mothers who were practice pediatric vaccination 86 (30.71\%) while 194 (69.28\%) did not practicing pediatric vaccination.

The maximum number of mothers 122 which was $(57.27 \%)$ award regarding the benefits of pediatric vaccination. Though, 91 which was $(42.72 \%)$ of mothers haven't the awareness. While the highest mothers 186 which was (66.42\%) haven't any awareness regarding the Expanded Program on Immunization additionally, 63 which was $(22.5 \%)$ said "No". Though 31 which was (11.07\%) said that they have awareness regarding the EPI. But about the zero to 2 years of pediatric-related diseases mother awareness 29 which was $(10.35 \%)$, while 251 mothers which were $(89.64 \%)$ haven't got awareness about the zero to 2 years of pediatric-related diseases. Furthermore, 212 mothers who had the awareness about pediatric related diseases asked to specify the leading cause of pediatric morbidity, 29 which were (13.67\%) said Polio, followed by another 29 which was $(13.67 \%)$ selected $29(13.67 \%)$ were responding as others, e.g. Fever and Flu. 25 was (11.79\%) Hepatitis B, 23 was (10.84\%) Phenomena. 19 (8.96\%) Measles 16 (7.54\%) 
Neonatal Tetanus. $14(6.60 \%)$ Malaria $12(5.66 \%)$ pediatric Tuberculosis. $9(4.24 \%)$ Jaundice. 4 (1.88\%) Pertussis, While $3(1.41 \%)$ Diphtheria was the leading cause of pediatric morbidity.280 respondents who had the awareness in Pakistan Pediatric vaccination been carried out for which disease asked to indicate the 63 which was $22.5 \%$ had the awareness followed by 217 which was $77.5 \%$ said they hadn't got awareness.

Table: 3

Knowledge of pediatric health risk

\begin{tabular}{|c|c|c|c|c|}
\hline & \multicolumn{2}{|l|}{ Yes } & \multicolumn{2}{|l|}{ No } \\
\hline & $\mathrm{F}$ & $\%$ & \multicolumn{2}{|l|}{$\mathrm{F}$} \\
\hline $\begin{array}{l}\text { Do you know about the common reason } \\
\text { for Pediatric health risk? }\end{array}$ & 71 & $25.35 \%$ & 209 & $74.64 \%$ \\
\hline \multicolumn{5}{|c|}{ What is the most common reason for Pediatric health risk? } \\
\hline $\begin{array}{l}\text { Pediatric health risk Reasons } \\
\end{array}$ & \multicolumn{2}{|c|}{$\mathrm{F}$} & \multicolumn{2}{|l|}{$\%$} \\
\hline Polio disease & \multicolumn{2}{|l|}{03} & \multicolumn{2}{|l|}{1.07} \\
\hline Tetanus disease & \multicolumn{2}{|l|}{00} & \multicolumn{2}{|l|}{0.00} \\
\hline Measles disease & \multicolumn{2}{|l|}{03} & \multicolumn{2}{|l|}{1.07} \\
\hline Diphtheria disease & \multicolumn{2}{|l|}{01} & \multicolumn{2}{|l|}{0.35} \\
\hline Pertussis disease & \multicolumn{2}{|l|}{01} & \multicolumn{2}{|l|}{0.35} \\
\hline Hepatitis B disease & \multicolumn{2}{|l|}{01} & \multicolumn{2}{|l|}{0.35} \\
\hline Hib Phenomena disease & \multicolumn{2}{|l|}{06} & \multicolumn{2}{|l|}{2.14} \\
\hline Meningitis disease & \multicolumn{2}{|l|}{01} & \multicolumn{2}{|l|}{0.35} \\
\hline Tuberculosis disease & \multicolumn{2}{|l|}{02} & \multicolumn{2}{|l|}{0.71} \\
\hline Jaundice disease & \multicolumn{2}{|l|}{04} & \multicolumn{2}{|l|}{1.42} \\
\hline Diarrhea disease & \multicolumn{2}{|l|}{07} & \multicolumn{2}{|l|}{2.5} \\
\hline Malaria disease & \multicolumn{2}{|l|}{02} & \multicolumn{2}{|l|}{0.71} \\
\hline Malnutrition relate disease & 25 & & 8.92 & \\
\hline Mothers awareness & 71 & & 24.90 & \\
\hline Medical infrastructure & 18 & & 6.42 & \\
\hline Low immunity & 71 & & 25.35 & \\
\hline $\begin{array}{l}\text { Social barriers prevent access to basic } \\
\text { medical resources }\end{array}$ & 58 & & 20.71 & \\
\hline Birth defects & 00 & & 0.00 & \\
\hline Preterm birth & 00 & & 0.00 & \\
\hline Respiratory and cardiovascular disorders & 02 & & 0.71 & \\
\hline Age of mother at birth & 04 & & 1.42 & \\
\hline Total & 280 & & $100 \%$ & \\
\hline & Yes & & No & \\
\hline $\begin{array}{l}\text { Do you know which diseases are currently } \\
\text { the most common among Pediatric } \\
\text { mortality? }\end{array}$ & 29 & $10 \%$ & 251 & $90 \%$ \\
\hline
\end{tabular}




\begin{tabular}{|l|l|l|}
\hline Vaccine Preventable Disease & F & $\%$ \\
\hline Vaccine Preventable Disease Polio & 03 & 10.34 \\
Vaccine Preventable Disease Tetanus & 00 & 0.00 \\
Vaccine Preventable Disease Measles & 03 & 10.34 \\
Vaccine Preventable Disease Diphtheria & 01 & 3.44 \\
Vaccine Preventable Disease Pertussis & 01 & 3.44 \\
Vaccine Preventable Disease Hepatitis B & 01 & 3.44 \\
Vaccine Preventable Disease Phenomena & 06 & 20.68 \\
Vaccine Preventable Disease Meningitis & 01 & 3.44 \\
Vaccine Preventable Disease Tuberculosis & 02 & 6.89 \\
Vaccine Preventable Disease Diarrhea & 13 & 44.81 \\
\hline Total & 29 & $100 \%$ \\
\hline
\end{tabular}

Table.03 shown that 71 which was $(25.35 \%)$ mother had the knowledge about the common reason for Pediatric health risk, while 209 which was $74.64 \%$ mother hadn't the knowledge. Additionally, the maximum mothers 71 which was $(25.35 \%)$ had the knowledge and said low immunization against the infectious diseases was the common reason for pediatric health risk. Though 58 which were $(20.71 \%)$ said social barriers prevent access to basic medical resources.50which were $(17.85 \%)$ mothers said the mother's level of educations. 25 which was (8.92\%) said Malnutrition. 21which were (7.5\%) Environmental conditions. 18 which was $(6.42 \%)$ said the Medical infrastructure. 7which were $(2.5 \%)$ said Diarrhea. 6 which was (2.14\%) Hib Phenomena. 4 which was $(1.42 \%)$ said Jaundice. While 4 which were $(1.42 \%)$ said the age of the mother at birth, 3 which were (1.07\%) Tetanus, Another 3 which were (1.07\%) said Measles. 2 which were $(0.71 \%)$ said Tuberculosis. 2 which were $(0.71 \%)$ Malaria. But 2 which were $(0.71 \%)$ said respiratory and cardiovascular disorders. But then again 1 which were $(0.35 \%)$ said Diphtheria. 1 which were $(0.35 \%)$ said Pertussis. 1 which were $(0.35 \%)$ said Hepatitis B. Whereas $1(0.35 \%)$ of the mother answered with Meningitis as the most common reason for pediatric health risk.

280 mothers had the knowledge about diseases are currently the most common among Pediatric mortality 29 which was $10 \%$ said they had the knowledge while 251 which was $(90 \%)$ hadn't got knowledge. Asked to indicate the most common disease among the Pediatric mortality 7 which was (24.13\%) Diarrhea, 6 (20.68\%) Pneumonia, 4 (13.79\%) Jaundice. 3 (10.34\%) Poliomyelitis. Another 3 (10.34\%) answered Measles, 2 (6.89\%) Malaria. Another 2 (6.89\%) said Tuberculosis. 1 (3.44\%) said Diphtheria. 1 (3.44\%) said Pertussis 1 (3.44\%) Hepatitis B. While another 1 (3.44\%) of the responded as Meningitis as the most common disease in pediatric mortality. 
Table: 4

Perception regarding pediatric mortality and morbidity

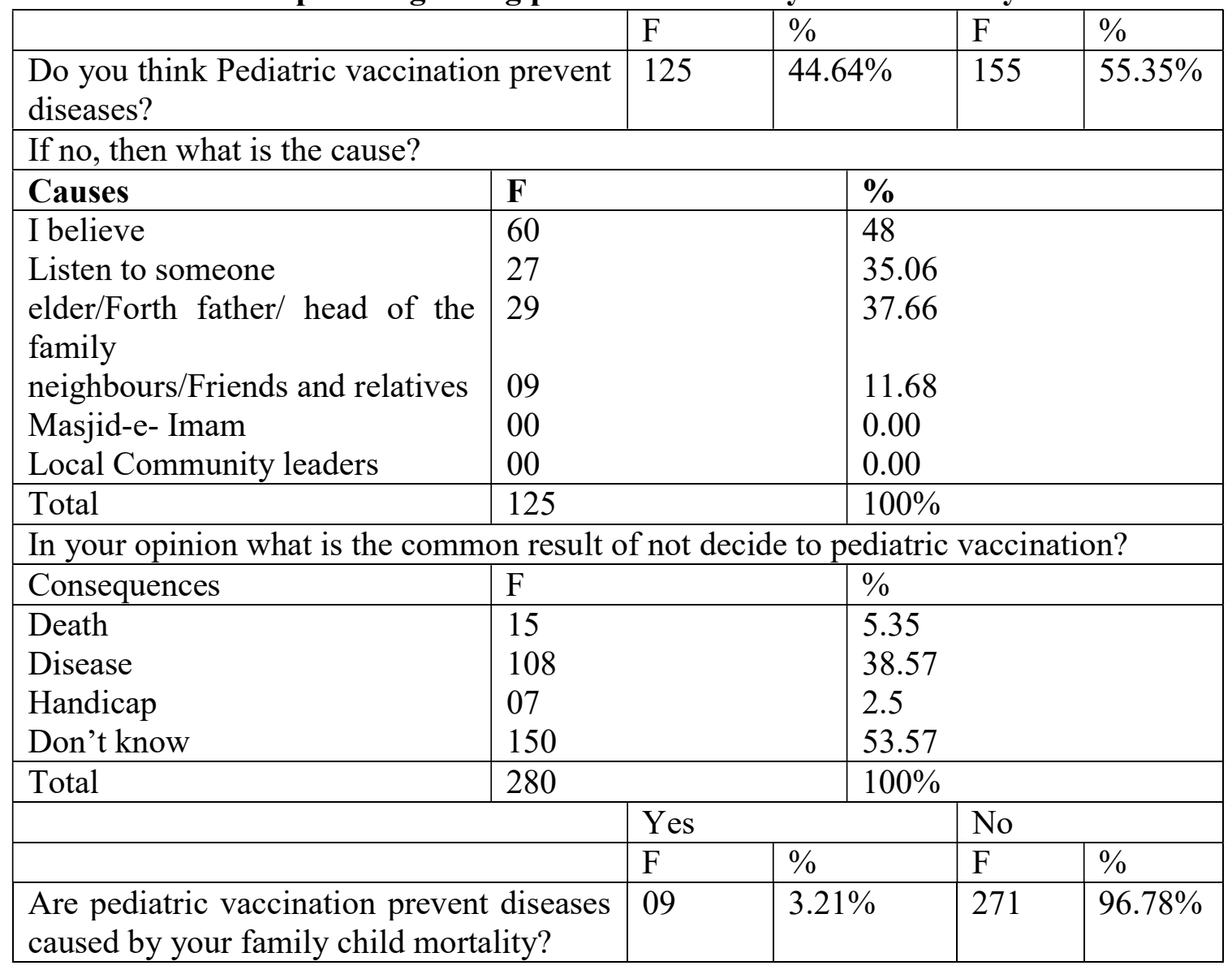

Table.03 shown that out of the total mothers 125 (44.64\%) said that Pediatric vaccination prevents diseases. But 155 (55.35\%) said that the vaccination didn't prevent diseases. While 57.1 out of the 77 mothers who thought Pediatric vaccination doesn't prevent diseases asked to indicate the reasons for their statement. $29(37.66 \%)$ heard from forth fathers, elders or head of the families. $27(35.06 \%)$ have heard from someone, 12 $(15.58 \%)$ have self-belief. However, $9(11.68 \%)$ of the mothers were following their friends, neighbours and far relatives. Also, in mothers opinion common result for not decide to pediatric vaccination, ask to indicate in the mother's opinion the common result for not decide to pediatric vaccination. The maximum mothers $120(53.57 \%)$ said that don't know, while 108 (38.57\%) said that diseases could be the result. Furthermore, 15 $(5.35 \%)$ said death. However, $7(2.5 \%)$ of the mothers said that the result could be the handicap as the common result for not decide to pediatric vaccination.

The mothers were asked to indicate pediatric vaccination caused by your family child mortality. 271 (96.78\%) mothers said that none of their child mortality occurred because 
of vaccination prevent diseases. Though, 9 (3.21\%) mothers said they have lost their family's children because of different diseases.

\section{Hypothesis}

Null Hypothesis: There is no relationship between the mother's awareness of and Pediatric routine vaccination status of children.

Alternative Hypothesis: There is a relationship between the mother's awareness of children and Pediatric routine vaccination status of children.

\section{Contingency Table}

\begin{tabular}{lccr}
\hline $\begin{array}{l}\text { Mother's Awareness } \\
\text { Vaccinated } \\
\text { Total } \\
\text { Yes }\end{array}$ & No & & \\
& & & \\
\hline Yes & & & \\
No & $29(9.3)$ & $61_{(80.7)}$ & $90(90)$ \\
Total & $00_{(19.7)}$ & $190_{(170.3)}$ & 190 \\
& $29_{(29)}^{(190)}$ \\
\end{tabular}

The results of Chi Square statistics are 68.29 and the $\mathrm{P}$ value is $<0.0010$.

It is significant

$\mathrm{X}^{2}=68.29$

$\mathrm{df}=1$

The value of $\mathrm{X}^{2}$ with the 1 degree of freedom, the significance level in the 0.05 is 3.84 .

The calculated value is bigger than the tabulated value i.e.68.29 $>3.841$, the research hypothesis is "There is a relationship between mother's awareness of children and Pediatric vaccination status." accepted and the null hypothesis" There is a relationship between the mother's awareness of children and Pediatric vaccination status of children is rejected.

\section{Findings of Statistical Analysis of Hypothesis}

$1^{\text {st }}$ hypothesis Results are Significant strong associations were found in between the Pediatric vaccination status and the mother'sawareness. Only 90 (32.14\%) of the children were vaccinated. While only $30.71 \%$ of mothers were practising of Pediatric vaccination. Pediatric Vaccination coverage was lower among mothers who got scores below the mother's awareness. 


\section{Discussion}

Pakistan is struggling in under 2 years of childhood vaccination. Mothers should understand that their children have to vaccinated against vaccine preventable diseases which only prevented via timely vaccination. There are so many reasons that may delay availing the health care for their children. Such barriers include low education, and lack of awareness, wrong perceptions and low health services (Pappas, Akhtar, Gergen, Hadden \& Khan, 2001).

In the current research these more question asked to the respondents

There are Respondents profile by the under-two year's children, The total household's under-two years children were 692 from which the highest number of children 373 (53.90\%) were female children and 319 (46.09\%) were male children.

Means female children are facing more problems in health in gadap town.

Respondents profile by the last child morbidity were asked, The Majority of the respondents, $57.85 \%$ of children got ill this month. This shows the health condition and sanitation condition of the areas.

Gadap is a rural, non-develop community of Karachi, Pakistan where paucity of oral and over-all health facilities are not succeeds. This study has been carried out to explore health status in the Gadap -low awareness association of child morbidity.

Respondents profile by the causes of child morbidity, Most of the respondents, $18.92 \%$ had the child morbidity due to Diphtheria

Majority of deaths and diseases occurred in the neonatal period, which enhances the importance of antena-tal care in the first month after birth. Infant/Child mortality in gadap can be reduced by improvement in the health care system at peripheral level.

Respondents profile by the children morbidity period were asked, Most of the respondents, 36.07\% of children have felt physical pain, fever or discomfort every month. Respondents profile by the causes of child mortality, The Majority of the respondents, 44.44\% of children died due to Hib Pneumonia.

Twenty polio cases have been occurred in Gadap's UC-4 during the past decade, with at least 10 of them having confirmed in the last five years. This shows the health conditions of the children of Gadap (Bhatti, 2018). 
Respondents profile by children given health facilities, the highest number of respondents, $27.14 \%$ of children were getting treatment from the quake. The shows the unavailability of health facilities in the area.

The 38 health facilities in Gadap Town are in limbo, Sindh General Hospital Murad Memon Goth, which was inaugurated by Chief Minister Murad Ali Shah, it started appealing patients but there is no preparation currently available to provide to inpatients due to a lack of doctors and staff and a non-functional operation theatre (The express Tribune 2017).

Respondents profile by the knowledge of infant-related diseases, The Majority of the respondents, $89.64 \%$ had no ideas about infant related diseases. This shows the unawareness level of the respondents.

The importance of the awareness level of health, awareness of Pediatric vaccination coverages have been shown in numerous reports (Luman, McCauley, Shefer, Chu. 2003 \& Prislin, Dyer, Blakely, Jonson, 1998). Current results show that mother's awareness and vaccination coverage level of children were more than the results.

Respondents profile by the most common reasons for infant health risks, Most of the respondents, $25.35 \%$ responded with low immunization against infectious diseases as the most common reason for infant's health risk.

The research found that mothers with lower levels of awareness. Two Studies done in the United States (Heininger, 2006 \& Benin, Wisler-Scher, Colson, Shapiro, Holmboe 2006). Results found that mothers with low awareness levels are less concerned about vaccine safety (Chen, Hibbs 1998).

Respondents profile by the most common disease in infant mortality, Most of the respondents, $24.13 \%$ said that Diarrhea was the most common disease in infant mortality. Different researches carried out in many nations, those children hadn't vaccinated( Stampi, Ricci, Ruffilli, Zanetti 2005\&Taylor, Darden PM, Slora, Hasemeier, Asmussen, Wasserman ,1997).we found that out of 280mothers' 194 children which were (70\%) hadn't vaccinated. Furthermore, 150 which was53.56 \% of mothers weren't in practices against pediatric vaccine-preventable diseases which already included in the Pakistan Pediatric routine vaccine schedule.

The lower mother awareness result found in the Spanish research and the results found 98.94\% low pediatric practices (Luman, Cauley, Shefer, Chu 2003). Furthermore, numerous mothers think that they did not have enough information or that awareness was not strong or right. However, the mothers have the doubts and supposed that the Pediatric vaccines could be dangerous, the high percentage of the mothers hadn't practiced Pediatric vaccination. 
As results have shown the lower vaccination coverage levels and the wrong perception of the pediatric health could have influenced changes in practices and awareness of the mothers.

\section{Conclusions}

The results of this study highlight the mother's awareness level furthermore, low awareness related to pediatric vaccine-preventable diseases. Low pediatric vaccine status and the responsible factors such as mother's perception, practices and associated with the low vaccination coverage. Therefore. The result also showed high rates of pediatric mortality and morbidity. The high rates of pediatric morbidity describe the perception and awareness of mothers. The pediatric health condition has been overlooked and it needs to progress.

It is essential to acknowledge that, the researchers measured the pediatric vaccination status which was associated with factors. The results showed that the pediatric vaccine status was low which shows that the practice, awareness, perception were responsible factors for the health condition of children and the occurrence of pediatric mortality.

The numerous studies had been conducted in many countries result that shows due to the mother's education the childhood vaccination status has upgraded and that is also an indicator of the children's health condition. Also, show that the majority of the mothers, had no idea about the health risk, benefits of vaccination, consequences, also, mothers hadn't comprehensive awareness about childhood vaccination. Additionally, mothers who didn't know about vaccine-preventable diseases.

On the other hand influences factors recognized by the researcher, that fully vaccinated children's status was low, the factors associated with low pediatric vaccine status mother's decision.

The results of the research also show that the morbidity rates of the children were high, These results showed that the children of Gadap Town are getting more ill frequently and the reasons for their morbidity has been shown was Diphtheria, Hib Phenomena, Measles, Diarrhea Meningitis, Pertussis, Hepatitis B, Jaundice, Tetanus and Malaria.

\section{Recommendations}

In line with the above conclusion, these written recommendations influence the children's health condition, additionally, increase the Pediatric vaccine status, and mother awareness level. 
The research variables of awareness and practice were associated with children's incomplete vaccine status. Henceforth, government and all private health providers have to work together with NGO's for the mother's awareness to enhance their awareness and upsurge their vision and clear perception health prevention exactly on the vaccine-

preventable diseases, its efficiency common risk factor and benefits. Health ministry should make extra efforts to promote the vaccines and underscore the problems of none Pediatric vaccination.

\section{References}

Ansari, R.M., Ansari, Y. \& Ansari, S.Y. (2015 Dec 4). Status of General Practice and Challenges to Healthcare System of Pakistan. Open Journal of Preventive Medicine, vol.5:12, pp.463- 467.

Benin, A.L., Wisler-Scher, D.J., Colson, E. \& Shapiro, E.D. (2006). Holmboe ES: Qualitative Analysis of the Mother's Decision-Making about Vaccines for Infants: The Importance of Trust. Paediatrics.117: 1532-41. 10.1542/peds.2005-1728. Retrieve from: ArticlePubMedGoogle Scholar.

Bhatti, W. (2018, October 18). Upshot of Pakistan's war on polio hangs on Gadap Town. Retrieved on February, 2019, from: https://www.thenews.com.pk/print/382639upshot-of-pakistan-s-war-on-polio-hangs-on-gadap-town.

CDC. (2000). Respiratory Syncytial Virus Activity-United States, 1999-2000 Season. MMWR. 49:1091-1093. [PubMed].

Chen, R.T. \& Hibbs, B. (1998). Vaccine Safety: Current and Future Challenges. Pediatric Ann. 27: 445-55. Retrieve from: ArticlePubMedGoogle Scholar.

Chernyshov, P.V. (2012). Gender Differences in Health-Related and Family Quality of Life in Young Children with Atopic Dermatitis. International Journal of Dermatology, vol.51:3, pp.290-294.

Daily Mail TV Programe (2018, February 20). Dying Young in Pakistan, Where Babies Face the Highest. Retrieved on November, 2018, from: https:/www.dailymail.co.uk/ wires/afp/article-5413593/Dying-young-Pakistan-babies-face-highest-risk.html.

End Polio Pakistan (2019) Polio Cases in Provinces. Retrieve May 2018 from: http://www.endpolio.com.pk/polioin-pakistan/polio-cases-in-provinces. 
Encyclopedia of the Nations. (2007). Asia and Oceania. Pakistan. Pakistan Health. (Online). Retrieved from: http://www.nationsencyclopedia.com/Asia-andOceania/Pakistan-HEALTH.html.UNICEF, State of the world Children 2004. Oxford University Press. New York.

Heininger, U. (2006). An Internet-Based Survey on Parental Attitudes towards Immunization. Vaccine. 24: 6351-5. 10.1016/j.vaccine.2006.05.029. Retrieved 2018 from: ArticlePubMedGoogle Scholar.

Holdsworth, C. \& Robinson, J. E. (2008). 'I've Never Ever let Anyone Hold the Kids While they've Got Ciggies: Moral Tales of Mothers Smoking Practices. Sociology of Health \& Illness, vol.30:7, pp.1086-1100.

Jennifer, L. \& Liang, DVM. (April 27, 2018). Prevention of Pertussis, Tetanus, and Diphtheria with Vaccines in the United States. Atlanta: Recommendations of the Advisory Committee on Immunization Practices. 67 (2)09-25.

Lorenz, C. \& Khalid, M. (2012, January). Influencing Factors on Vaccination Uptake in Pakistan: Journal of Pakistan Medical Association. Retrieved October, 2018, from: https://jpma.org.pk/article-details/3230.

Luman, ET., McCauley, MM., Shefer, A. \& Chu SY. (2003). Maternal Characteristics Associated with Vaccination of Young Children. Pediatrics; 111:1215-8. [PubMed]

The Express Tribune (2017, May 16). Health Centres Handed Over to HANDS Left in Limbo. Retrieved on October, 2018, from: https://tribune.com.pk/story/1400325/health-centres-handed-hands-left-limbo/.

Mathers, C.D., Lopez, A.D. \& Murray, C.J.L. (2006). The Burden of Disease and Mortality by Condition: Data, Methods, and Results for 2001. Oxford University Press, New York: 3.45-240.

Name of Areain Population Administrative Units. $6^{\text {th }}$ Population and of Census Housing (2017) Pakistan Retrieve 2018 from: http://www.pbs.gov.pk/sites/default/files/ population_census/Administrative\%20Units.pdf.

Nizar H, Chagani P. (2016). Analysis of Health Care Delivery System in Pakistan and Singapore. International Journal of Nursing, vol.8:2, pp.21-26. 
Pappas, G., Akhtar, T., Gergen, PJ., Hadden, WC. \& Khan AQ. (2001). Health Status of the Pakistani Population: A Health Profile and Comparison with the United States. Am J Public Health. 91:93-8.

Payne, S., Townend, J., Jasseh, M., Lowe, Jallow Y. \& Kampmann B. (Mar 2014). Achieving Comprehensive Pediatric Immunization: An Analysis of Obstacles and Opportunities in the Gambia. Health Policy Plan, vol.29:2, pp.193-203.

Population of Cities in Pakistan (2018). Retrieved from: http://www.pbs.gov.pk/content/ population-census.

Prislin, R., Dyer, JA., Blakely, CH. \& Jonson Ch D. (1998). Immunization Status and Socio-Demographic Characteristics: The Mediating Role of Beliefs, Attitudes and Perceived Control. Am J Publ Health.;88:1821-6. doi: 10.2105/AJPH.88.12.1821. [PMC free article] [PubMed] [Cross Ref].

Revolvy, L. (2018). Demographics of Pakistan. Retrieved on January, 2019, from: https://www.revolvy.com/page/Demographics-of-Pakistan.

Rudan1, I. (1 June 2013). The Leading Priority is also the Greatest Opportunity: 3(20472978), 108-116. doi:10.7189/jogh.03.010101.

Rutherford, ME., Dockerty, JD. \& Jasseh, M. et al. (2009). Preventive Measures in Infancy to Reduce Under-Five Mortality: A Case-Control Research in the Gambia. Tropical Medicine and International Health, vol.14, pp.149-55.

Stampi, S., Ricci, R., Ruffilli, I. \& Zanetti, F. (2005). Compulsory and Recommended Vaccination in Italy: Evaluation of Coverage and Non-Compliance between 1998-2002 in Northern Italy. BMC Public Health. 5: 42-10.1186/1471-2458-5-42.

Taylor, J.A., Darden, P.M., Slora, E., Hasemeier, C.M., Asmussen, L. \& Wasserman, R. (1997). The Influence of Provider behaviour, Parental Characteristics, and a Public Policy Initiative on the Immunization Status of Children Followed by Private Pediatricians: A Study from Pediatric Research in Office Settings. Pediatrics.;99:209-15. doi: 10.1542/peds.99.6.e9. [PubMed] [Cross Ref]

Tomes, H. \& Rickel, A. (1996). Psychologist's Contributions to the Policy Process, In R P Lorion, I. Iscoe, P H DelLeon, \& G R VanenBos (Eds.), Psychology and public policy: Balancing public service and professional need (pp 325-329).Washington, DC: American Psychological Association. 
The World Bank (2017). Infant Mortality Rate, (per 1,000 live births). Retrieved on July, 2018, from: https://data.worldbank.org/indicator/SP.DYN.IMRT.IN?page=

UNICEF (2017). Neonatal Mortality - UNICEF DATA. Retrieved on Jan 2018, from: https://www.unicef.org/publications/files/Children_Mortality_Report_2017.pdf.

UNICEF (March 2018). Child Mortality. Retrieved on January 07, 2019, from: https://data.unicef.org/topic/child-survival/under-five-mortality/.

United Nation (2015, September 09). Millennium Development Goals. Retrieved on November 29, 2018, from: https://www.undp.org/content/undp/en/home/ sdgoverview/mdg_goals.html.

UNICEF (2018). Vaccination and Immunization Statistics. Retrieved on January 3, 2019, from: https://data.unicef.org/topic/child-health/immunization/.

UNICEF (2017). Neonatal Mortality - UNICEF DATA, Retrieved on April 2018, from: https://www.unicef.org/publications/files/Children_Mortality_Report_2017.pdf.

VanderStoep, S. W. \& Johnston, D. (2009). Research Methods for Everyday Life: Blending Qualitative and Quantitative Approaches. San Francisco: Jossey-Bass. 1; pp 48-58.

Wiysonge, C.S., Uthman, O.A., Ndumbe, P.M. \& Hussey GD. (2012). Individual and Contextual Factors Associated With Low Pediatric Immunization Coverage in Sub-Saharan Africa: A Multilevel Analysis. PLoS ONE, 7 (5): e37905. doi: 10.1371/journal.pone.0037905.

WHO (2013, July 29). Executive Summary. Retrieved on December 19, 2018, from: https://www.who.int/whr/1998/media_centre/executive_summary6/en/.

WHO (2019, February 25). Data, Statistics and Graphics. Retrieved on October, 28, 2018, from: http://www.who.int/immunization/monitoring_surveillance/data/en/.

WHO (2017). Health Profile Pakistan Retrieved on September, 2018, from: https://www.worldlifeexpectancy.com/country-health-profile/pakistan.

WHO (2010). Vaccine-Preventable Diseases: Monitoring System. 2010 Global Summary. Geneva, Switzerland: World Health Organization. Retrieve 2018 from from;whqlibdoc.who.int/hq/201 0/WHO_IVB_2010_eng.pdf? ua=1. 
WHO (2010). Vaccine-Preventable Diseases: Monitoring System-2010 Global Summary. Geneva, Switzerland: World Health Organization. Retrieved on April 2019, from: whqlibdoc.who.int/hq/2010/WHO_IVB_2010_eng.pdf? ua=1.

WHO (2016). Infant Mortality Retrieved on Feb 2019, from: http://www.who.int/gho/ children_health/mortality/neonatal_infant_text/e/.

WHO (2018). Infant Mortality. Retrieved on March 08, 2018, from: http://www.who.int/gho/children_health/mortality/neonatal_infant_text/en/.

Sadaf Abid Ali is Ph.D Scholar in the Department of Social Work, University of Karachi.

Dr. Sumera Ishrat is an Assistant Professor in the Department of Social Work, University of Karachi. 